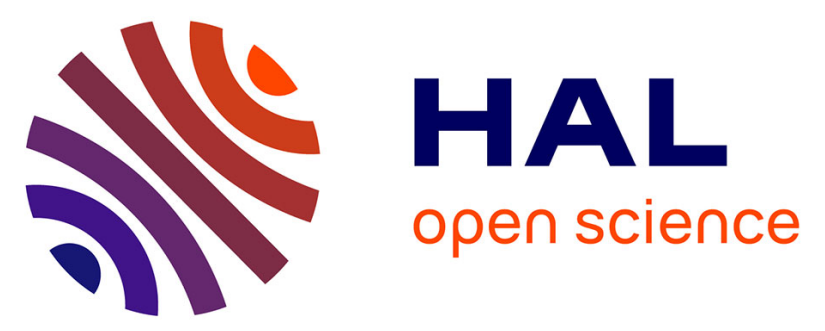

\title{
Lipidomic approach in young adult triathletes: effect of supplementation with a polyphenols-rich juice on neuroprostane and F2 -dihomo-isoprostane markers
}

Libia Alejandra Garcia-Flores, Sonia Medina, Camille Oger, Jean-Marie Galano, Thierry Durand, Roberto Cejuela, José Miguel Martínez-Sanz, Federico Ferreres, Ángel Gil-Izquierdo

\section{To cite this version:}

Libia Alejandra Garcia-Flores, Sonia Medina, Camille Oger, Jean-Marie Galano, Thierry Durand, et al.. Lipidomic approach in young adult triathletes: effect of supplementation with a polyphenolsrich juice on neuroprostane and F2 -dihomo-isoprostane markers. Food and Function, 2016, 10.1039/c6fo01000h . hal-02593004

\section{HAL Id: hal-02593004 \\ https://hal.science/hal-02593004}

Submitted on 15 May 2020

HAL is a multi-disciplinary open access archive for the deposit and dissemination of scientific research documents, whether they are published or not. The documents may come from teaching and research institutions in France or abroad, or from public or private research centers.
L'archive ouverte pluridisciplinaire HAL, est destinée au dépôt et à la diffusion de documents scientifiques de niveau recherche, publiés ou non, émanant des établissements d'enseignement et de recherche français ou étrangers, des laboratoires publics ou privés. 


\title{
Lipidomic approach in young adult triathletes: effect of supplementation with a polyphenols-rich juice on neuroprostane and $\mathrm{F}_{\mathbf{2}}$-dihomo-isoprostane markers
}

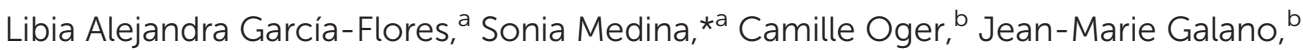 \\ Thierry Durand, ${ }^{b}$ Roberto Cejuela, ${ }^{c}$ José Miguel Martínez-Sanz, ${ }^{c}$ Federico Ferreres ${ }^{a}$ \\ and Ángel Gil-Izquierdo*a
}

\begin{abstract}
The aim of the this study was to determine the effect of a polyphenols-rich juice (aronia-citrus juice, ACJ) on $\mathrm{F}_{4}$-neuroprostanes and $\mathrm{F}_{2}$-dihomo-isoprostanes-markers of oxidative stress associated with the central nervous system (CNS)-in 16 elite triathletes under a controlled diet for triathlon training (145 days). In the triathletes, a decrease of the lipid peroxidation markers after ACJ intake, associated with neuronal membrane degradation (10-epi-10- $\mathrm{F}_{4 \mathrm{t}}$-neuroprostane and 10- $\mathrm{F}_{4 \mathrm{t}}$-neuroprostane), was observed when compared with placebo stage values. Regarding the $\mathrm{F}_{2}$-dihomo-isoprostanes, a significant decrease of the neuromotor system damage biomarkers (17- $\mathrm{F}_{2 \mathrm{t}}$-dihomo-isoprostane) with an increase of training load during the study was observed, although the decrease of the load training at the last stage showed a significant increase of the values of ent-7-(RS)-7- $\mathrm{F}_{2 \mathrm{t}}$-dihomo-IsoP, suggesting a possible role in adaptation post-training. On the other hand, the changes in the excretion of 17-epi-17- $\mathrm{F}_{2 \mathrm{t}}$-dihomo-IsoP provided a positive connection between physical exercise and ACJ intake. Thus, the results showed in this clinical study in young triathletes will help to elucidate novel interactions and mechanisms between the excretion of lipid peroxidation metabolites from CNS, supplementation of polyphenols-rich juice in the diet and physical exercise during a training season.
\end{abstract}

\section{Introduction}

Exercise-induced reactive oxygen species (ROS) production could be an important signaling pathway to induce biological adaptations to training. ${ }^{1,2}$ In addition, regarding the effect of exercise on the brain, regular and moderate aerobic exercise appears to promote the antioxidant capacity, but anaerobic or high-intensity exercise, aerobic-exhausted exercise, or the combination of both types of training could worsen the antioxidant response. ${ }^{3}$ The literature shows that polyphenols (abundant in plants and plant-derived foods such as fruits and vegetables) can provide protection against exercise-induced muscle damage and oxidative stress (OS) thanks to their antioxidant and antiinflammatory properties. ${ }^{4,5}$ There has also been growing reco-

\footnotetext{
${ }^{a}$ Dept. of Food Science and Technology. CEBAS-CSIC. Campus de Espinardo 25, 30100 Espinardo, Murcia, Spain. E-mail: smescudero@cebas.csic.es, angelgil@cebas.csic.es; Fax: +34 968396213; Tel: +34 968396363, 6253 ${ }^{b}$ Institut des Biomolécules Max Mousseron, UMR 5247 CNRS-University of Montpellier - ENSCM, Montpellier, France

${ }^{c}$ Faculty of Education, University of Alicante, Campus de San Vicent del Raspeig, Alicante, Spain
}

gnition of the possible beneficial influence of polyphenols on the development and health of brain structure and function, 6,7 as well as their positive effects, which involve a decrease in oxidative/inflammation damage in the nervous system. ${ }^{8,9}$

The use of antioxidant supplementation is common in athletes, primarily to prevent overproduction of ROS and their deleterious impact on cells and tissues through lipid and protein protection. There is evidence that beverages, such as fruit juice, containing a diversity of polyphenol compounds can have a favorable impact on human health. ${ }^{5,9}$ It has been mentioned that fruit juices can provide a blend of polyphenols in a single serving of the drink that cannot be obtained from a portion of fruit. ${ }^{10,11}$ For example, the combination of Aronia (Aronia melanocarpa) with citrus juices has provided synergistic effects of flavanones plus anthocyanins, among other bioactive compounds. ${ }^{12}$ Black chokeberry (Aronia melanocarpa) contains high amounts of polyphenol compounds that are bioavailable and show health-promoting properties for humans by different mechanisms. ${ }^{13}$ Among them, the intake of this berry may be beneficial against OS, in both humans and animals. ${ }^{14}$ In addition, citrus flavonoids have antioxidant and antiinflammatory bioactivities. Previous in vitro and in vivo studies showed that these flavonoids exert neuroprotection at high 
and low doses. ${ }^{15}$ Supplementation with the polyphenols-rich juice used in this study-aronia-citrus juice (ACJ) - may provide health protection to triathletes (200 $\mathrm{mL}$ per day), according to previously published results. ${ }^{13}$ In fact, the bioavailability of flavanones (eriodictyol and hesperetin) in the triathletes was augmented after the ACJ intake (during 2 weeks) by the physical exercise compared to sedentary volunteers. Besides, the intake of this ACJ, in conjunction with adequate training, was able to influence the plasmatic and urinary values of OS biomarkers (15- $\mathrm{F}_{2 \mathrm{t}}$-IsoP; also termed 8-iso-prostaglandin- $\mathrm{F}_{2 \alpha}$ urinary biomarker, as well as the biomarkers guanosine-3',5'-cyclic monophosphate and 8-hydroxyguanine analyzed in plasma samples). ${ }^{16}$ Llorach et al. recently published a metabolomic study in healthy volunteers after regular ACJ intake $(250 \mathrm{~mL}$ per day) for 16 weeks and found an association with markers of intake of the components of juice: proline betaine, ferulic acid, and two unknown mercapturate derivatives. ${ }^{17}$

Regarding lipid oxidation markers, $\mathrm{F}_{2}$-dihomo-isoprostanes ( $\mathrm{F}_{2}$-dihomo-IsoPs) and $\mathrm{F}_{4}$-neuroprostanes ( $\mathrm{F}_{4}$-NeuroPs) are formed by a free radical, non-enzymatic mechanism from adrenic acid (AdA, C22:4 n-6) ${ }^{18,19}$ and docosahexaenoic acid (DHA, C22:6 n-3), ${ }^{20}$ respectively. $\mathrm{F}_{4}$-NeuroPs originate from DHA, an essential constituent of nervous tissue, highly enriched in neurons and highly prone to oxidation. ${ }^{21} \mathrm{~F}_{2^{-}}$ dihomo-IsoPs are specific markers generated from AdA and are potential markers of free radical damage to myelin in the human brain. ${ }^{18}$ Currently, researchers tend to focus more on the assessment of these biomarkers in disease conditions and their increase in different biological fluids. ${ }^{19,22-24}$ Besides, no attention has been paid to the investigation of these central nervous system (CNS) degradation markers and their relationship with physical exercise, to the ability of nutrition with functional foods enriched in polyphenols to attenuate to this type of OS generation, or to the elucidation of potential pathways of the OS biomarkers with exercise adaptation and/or the effect of functional foods on the CNS.

Based on the foregoing statements, the aim of this work was to evaluate urinary biomarkers of OS associated with the CNS, namely four $\mathrm{F}_{4}$-NeuroPs and four $\mathrm{F}_{2}$-dihomo-IsoPs, and whether supplementation of the diet with one serving $(200 \mathrm{~mL}$ per day) of ACJ for 45 days could produce changes in these OS biomarkers. In this study, the identification was carried out by UHPLC-QqQ-MS/MS thanks to its superior advantages to techniques used in other studies to distinguish the regioisomers and diastereomers of the metabolites in samples. ${ }^{20}$ This is the first study to investigate these CNS degradation markers in relation to physical exercise, as well as the influence of nutrition with functional foods enriched in polyphenols.

\section{Materials and methods}

\subsection{Physical characteristics of participants}

The anthropometric measurements were performed according to the International Society for the Advancement of Kinanthropometry (ISAK: http://www.isakonline.com), in all cases by the same internationally certified anthropometrist (level 2 ISAK) to minimize the technical error of the measurement. The body composition was determined by GREC Kineanthropometric consensus, using a model that consists of: total fat by Withers' formula, ${ }^{25}$ lean weight by a previous procedure, ${ }^{26}$ and residual mass by the difference in weight (Table 1).

\subsection{Dietary intake of participants}

The diet was kept constant to avoid any interference with urinary analysis (Table 2). The calculation of the dietary parameters and caloric intake was accurately designed and overviewed during the experimental intervention by nutritionists and specific software was used for the calculation. The data were calculated using the software available on the website (http://www.easydiet.es), with the additional assistance of the Spanish and USDA databases (http://www.bedca.net/ and http://www.nal.usda.gov/fnic/foodcomp/search/). The dietary assessment and planning for our volunteers were estimated based on their energy needs, ${ }^{27}$ on their energy expenditure, ${ }^{28}$ and on different recommendations for triathletes ${ }^{29}$ as well as sports men/women. ${ }^{30}$ The dietary fulfillment was individually conducted for each elite triathlete by the University of Alicante nutritionists (Chief responsible for the dietary control: Dr José Miguel Martínez-Sanz). Dietary information was obtained via $24 \mathrm{~h} \mathrm{recall},{ }^{31}$ in which they described in detail all foods and drinks consumed 24 hours prior to each provision of urine.

2.2.1 Aronia-citrus juice and placebo beverage. The juice composition was based on a mixture of citrus juice (95\%) with 5\% Aronia melanocarpa juice, based on a drink model developed before. ${ }^{32}$ The composition was developed in the industry at pilot scale with organoleptically acceptable criteria, to mimic the flavonoids composition of the original beverage. The supplementation with this natural fruit juice has been used in other studies, as aforesaid in the introduction, the daily dose being around $200 \mathrm{~mL}$ (ref. 13 and 17) in healthy subjects. The nutrient content and caloric supply of the ACJ are summarized in Table 3, as well as the contents of fruit flavanones, flavones, and anthocyanins. The results are expressed as milligrams per serving of juice. One serving of juice corresponds to $240 \mathrm{~mL}$ according to the US FDA (US Food and Drug Administration), but in this study it was adjusted to $200 \mathrm{~mL}$ to adapt to the caloric requirements of the triathletes (represented only $2.6 \%$ of the calories of the diet).

The placebo beverage was a mixture of water, authorized red dye, flavoring, and sweetener, with sensory characteristics very similar to those described for the ACJ. This placebo drink has been used in two other previous studies. ${ }^{17,33}$

\subsection{Training load}

Triathlon is a sport where three exercises (swimming, cycling, and running) are performed in a continuous way, these three are being the most common exercises among human forms of locomotion. ${ }^{34}$ The quantification of training programs was addressed to evaluate their effects on physiological adaptation and subsequent performance. ${ }^{35}$ The training load quantification was performed using the objective load scale (ECOs); to 
Table 1 Physical and metabolic characteristics and training loads of the elite triathletes

\begin{tabular}{|c|c|c|c|c|c|}
\hline \multirow[b]{2}{*}{ Physical characteristics } & \multicolumn{5}{|c|}{ Stages of study } \\
\hline & $\mathrm{CB}$ & $\mathrm{CT}$ & Placebo & ACJ & CP-T \\
\hline \multicolumn{6}{|l|}{ Male $(n=10)$} \\
\hline Age $(y)$ & $19.0 \pm 1.7$ & $19.0 \pm 1.7$ & $19.0 \pm 1.7$ & $19.4 \pm 1.3$ & $19.6 \pm 1.3$ \\
\hline Weight (kg) & $69.0 \pm 6.2$ & $69.0 \pm 6.4$ & $70.7 \pm 6.9$ & $71.2 \pm 4.6$ & $72.2 \pm 6.8$ \\
\hline Height (m) & $1.8 \pm 0.1$ & $1.8 \pm 0.1$ & $1.8 \pm 0.1$ & $1.8 \pm 0.1$ & $1.8 \pm 0.1$ \\
\hline $\mathrm{BMI}^{a}\left(\mathrm{~kg} \mathrm{~m}^{-2}\right)$ & $22.2 \pm 1.0$ & $22.2 \pm 1.0$ & $21.7 \pm 1.4$ & $21.6 \pm 1.3$ & $21.8 \pm 1.7$ \\
\hline Total fat $(\mathrm{kg})$ & $9.2 \pm 2.8$ & $8.8 \pm 2.6$ & $8.0 \pm 1.7$ & $6.4 \pm 2.8$ & $6.8 \pm 1.2$ \\
\hline Lean weight $(\mathrm{kg})$ & $31.4 \pm 2.1$ & $30.5 \pm 2.7$ & $31.6 \pm 3.0$ & $33.8 \pm 3.2$ & $32.4 \pm 2.4$ \\
\hline Subscapular skinfold (mm) & $9.6 \pm 3.0$ & $9.5 \pm 2.1$ & $9.1 \pm 1.7$ & $8.6 \pm 2.0$ & $8.6 \pm 1.8$ \\
\hline Triceps skinfold (mm) & $8.9 \pm 3.0$ & $9.7 \pm 2.6$ & $8.7 \pm 2.1$ & $7.4 \pm 2.4$ & $7.3 \pm 1.5$ \\
\hline Biceps skinfold (mm) & $5.4 \pm 2.4$ & $4.7 \pm 1.5$ & $4.1 \pm 0.6$ & $4.5 \pm 1.5$ & $3.7 \pm 0.4$ \\
\hline Iliac crest skinfold (mm) & $12.0 \pm 2.6$ & $13.1 \pm 4.1$ & $12.5 \pm 4.2$ & $11.2 \pm 3.4$ & $9.6 \pm 2.5$ \\
\hline Supraspinale skinfold (mm) & $9.0 \pm 2.6$ & $8.9 \pm 2.8$ & $8.7 \pm 2.5$ & $7.6 \pm 1.9$ & $6.7 \pm 1.4$ \\
\hline Abdominal skinfold (mm) & $16.4 \pm 8.0$ & $15.5 \pm 6.8$ & $14.5 \pm 5.9$ & $11.8 \pm 5.2$ & $10.0 \pm 3.7$ \\
\hline Front thigh skinfold (mm) & $14.9 \pm 4.4$ & $14.0 \pm 4.4$ & $11.5 \pm 2.3$ & $10.1 \pm 2.9$ & $10.0 \pm 2.5$ \\
\hline Medial calf skinfold (mm) & $9.0 \pm 3.0$ & $9.5 \pm 3.1$ & $8.2 \pm 2.1$ & $7.2 \pm 2.3$ & $7.3 \pm 1.8$ \\
\hline Training loads ECOs & $37.5 \pm 5.5$ & $1008 \pm 105$ & $923 \pm 119$ & $923 \pm 119$ & $552 \pm 45$ \\
\hline \multicolumn{6}{|l|}{ Female $(n=6)$} \\
\hline Age $(y)$ & $21.0 \pm 3.0$ & $21.0 \pm 3.0$ & $21.08 \pm 3.0$ & $21.0 \pm 3.0$ & $21.0 \pm 3.0$ \\
\hline Weight (kg) & $54.8 \pm 12.2$ & $54.8 \pm 11.6$ & $56.2 \pm 4.8$ & $54.4 \pm 5.0$ & $53.1 \pm 2.9$ \\
\hline Height (m) & $1.6 \pm 0.1$ & $1.6 \pm 0.1$ & $1.6 \pm 0.1$ & $1.6 \pm 0.1$ & $1.6 \pm 0.1$ \\
\hline $\mathrm{BMI}^{a}\left(\mathrm{~kg} \mathrm{~m}^{-2}\right)$ & $21.2 \pm 4.1$ & $21.2 \pm 4.1$ & $20.7 \pm 1.3$ & $21.6 \pm 2.4$ & $20.5 \pm 1.6$ \\
\hline Total fat $(\mathrm{kg})$ & $8.7 \pm 4.1$ & $8.9 \pm 4.7$ & $9.2 \pm 0.9$ & $7.5 \pm 1.2$ & $7.3 \pm 1.4$ \\
\hline Lean weight $(\mathrm{kg})$ & $20.8 \pm 3.6$ & $20.6 \pm 2.7$ & $20.8 \pm 2.4$ & $19.4 \pm 2.8$ & $20.9 \pm 2.0$ \\
\hline Subscapular skinfold (mm) & $12.7 \pm 6.7$ & $13.4 \pm 8.2$ & $11.7 \pm 2.5$ & $10.7 \pm 1.9$ & $9.9 \pm 2.8$ \\
\hline Triceps skinfold (mm) & $16.3 \pm 2.3$ & $18.4 \pm 3.8$ & $19.3 \pm 5.4$ & $16.1 \pm 4.6$ & $17.4 \pm 4.6$ \\
\hline Biceps skinfold (mm) & $10.3 \pm 2.8$ & $9.8 \pm 3.2$ & $7.2 \pm 0.4$ & $5.7 \pm 1.0$ & $5.7 \pm 1.3$ \\
\hline Iliac crest skinfold (mm) & $19.7 \pm 4.5$ & $17.1 \pm 6.9$ & $20.9 \pm 4.5$ & $17.3 \pm 3.7$ & $13.7 \pm 4.3$ \\
\hline Supraspinale skinfold (mm) & $14.3 \pm 6.5$ & $14.4 \pm 6.9$ & $15.0 \pm 1.0$ & $12.8 \pm 2.1$ & $11.6 \pm 2.5$ \\
\hline Abdominal skinfold (mm) & $23.1 \pm 5.9$ & $23.6 \pm 6.9$ & $24.5 \pm 4.7$ & $21.3 \pm 4.1$ & $17.9 \pm 4.6$ \\
\hline Front thigh skinfold (mm) & $27.2 \pm 5.2$ & $26.4 \pm 5.0$ & $25.8 \pm 3.6$ & $23.8 \pm 12.5$ & $26.0 \pm 5.4$ \\
\hline Medial calf skinfold (mm) & $14.8 \pm 3.8$ & $13.9 \pm 3.0$ & $15.7 \pm 2.1$ & $12.5 \pm 1.8$ & $14.4 \pm 2.9$ \\
\hline Training loads ECOs & $37.5 \pm 5.5$ & $1008 \pm 105$ & $923 \pm 119$ & $923 \pm 119$ & $552 \pm 45$ \\
\hline
\end{tabular}

${ }^{a}$ Body mass index. CB; Control Baseline, CT; Control Training, ACJ; Aronia-Citrus Juice, CP-T; Control Post-Treatment.

Table 2 Dietary parameters and caloric intake of the triathletes during the study

\begin{tabular}{|c|c|c|}
\hline & Male triathletes & Female triathletes \\
\hline Energy intake (kcal) & $2820.0 \pm 241.2$ & $2072.6 \pm 223.4$ \\
\hline Carbohydrate $\left(\mathrm{g} \mathrm{d}^{-1}\right)$ & $326.1 \pm 63.5$ & $211.3 \pm 43.9$ \\
\hline Dietary fiber $\left(\mathrm{g} \mathrm{d}^{-1}\right)$ & $27.3 \pm 7.4$ & $15.5 \pm 4.4$ \\
\hline Sugars $\left(\mathrm{g} \mathrm{d}^{-1}\right)$ & $121.3 \pm 33.9$ & $80.5 \pm 18.3$ \\
\hline Proteins $\left(\mathrm{g} \mathrm{d}^{-1}\right)$ & $133.7 \pm 12.9$ & $83.5 \pm 9.0$ \\
\hline Total lipids $\left(\mathrm{g} \mathrm{d}^{-1}\right)$ & $113.7 \pm 13.3$ & $107.1 \pm 14.4$ \\
\hline $\mathrm{SFA}^{a}\left(\mathrm{~g} \mathrm{~d}^{-1}\right)$ & $33.5 \pm 6.5$ & $29.6 \pm 4.4$ \\
\hline $\operatorname{MUFA}^{b}\left(\mathrm{~g} \mathrm{~d}^{-1}\right)$ & $56.5 \pm 5.5$ & $56.6 \pm 7.5$ \\
\hline $\operatorname{PUFA}^{c}\left(\mathrm{~g} \mathrm{~d}^{-1}\right)$ & $16.9 \pm 2.7$ & $15.9 \pm 6.7$ \\
\hline Vitamin $\mathrm{C}\left(\mathrm{mg} \mathrm{d}^{-1}\right)$ & $178.9 \pm 71.9$ & $135.0 \pm 60.4$ \\
\hline Vitamin $\mathrm{A}\left(\mu \mathrm{g} \mathrm{d}^{-1}\right)$ & $2970.0 \pm 913.9$ & $1427.4 \pm 573.1$ \\
\hline Vitamin $\mathrm{E}\left(\mathrm{mg} \mathrm{d}^{-1}\right)$ & $21.0 \pm 5.6$ & $13.9 \pm 3.4$ \\
\hline Vitamin D $\left(\mathrm{mg} \mathrm{d}^{-1}\right)$ & $988 . \pm 47.5$ & $751.6 \pm 163.0$ \\
\hline $\operatorname{Iron}\left(\mathrm{mg} \mathrm{d}^{-1}\right)$ & $20.9 \pm 2.4$ & $14.9 \pm 2.6$ \\
\hline Selenium $\left(\mathrm{mg} \mathrm{d}^{-1}\right)$ & $149.8 \pm 21.5$ & $103.0 \pm 17.4$ \\
\hline
\end{tabular}

Dietary parameters and caloric intake of the triathletes during the study. ${ }^{a}$ Saturated fatty acids. ${ }^{b}$ Monounsaturated fatty acids. ${ }^{c}$ Polyunsaturated fatty acids.
Table 3 Nutritional and phenolic composition of aronia-citrus juice

\begin{tabular}{ll}
\hline ACJ & $200 \mathrm{~mL}$ \\
\hline Energy intake (kcal) & 76 \\
Proteins (g) & 0.9 \\
Carbohydrate (g) & 18 \\
Fat (g) & 0.06 \\
Phenolic compounds & \\
Total flavonoids (mg) & $129.31 \pm 1.79$ \\
Hydroxycinnamic acids (mg) & $68.82 \pm 0.6$
\end{tabular}

The values are means \pm standard deviation $(n=3$, expressed as mg per $200 \mathrm{~mL}$ of juice). ${ }^{a}$ For more detailed analysis of the phenolic compounds from this juice, see ref. 16.

learn more about this scale, refer to the papers below. ${ }^{34,36}$ The training loads developed by triathletes in the present trial were similar to those found in other studies. ${ }^{13,37,38}$ The values of daily and weekly trainings have been summarized to assess the ECOs of each volunteer, depending on their physical characteristics and the intensity of the training program (the ECOs data presented are the average of the individual ECOs of the triathletes; Fig. 1). Briefly, and from a general point of view, the 


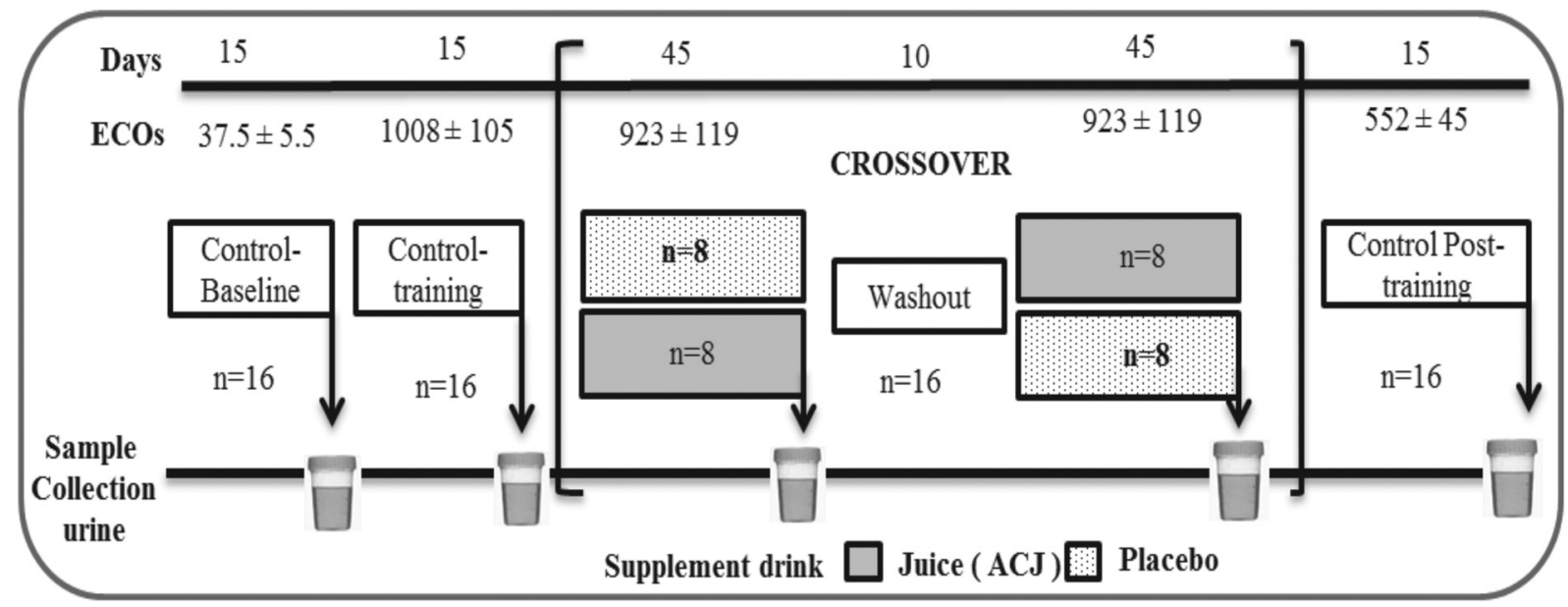

Fig. 1 Study design. This crossover study was randomized, double-blind, and placebo-controlled. Sixteen athletes $(n=16)$, randomly divided into two groups $(n=8$ ), were assigned supplementation with either $200 \mathrm{~mL}$ of ACJ (aronia-citrus juice) or $200 \mathrm{~mL}$ of placebo. After 45 days of supplementation and a 10 day washing-out period, the beverages were reversed. Urine samples were collected on the last day at the end of each stage. The training load was quantified by the Objective Load Scale (ECOs).

intensity was exponentially—not linearly—considered, with the aim of leveling off the total training stress for a given performance level. The volume was quantified by time and this allowed better comparison of different performance levels and terrain conditions (pavement, uneven laps). ${ }^{34}$

\subsection{Study design}

Sixteen Caucasian triathletes (6 training women and 10 training men), aged 19-21 years from the University of Alicante (Spain) agreed to participate in the project. The recruitment started on $28^{\text {th }}-29^{\text {th }}$ October 2010 and was completed on $24^{\text {th }}$ $25^{\text {th }}$ March 2011. The volunteers were non-smokers, had stable food habits, and did not receive any medication (including the specific absence of the acute administration of anti-inflammatory drugs) during the experimental procedure. The study was approved by the Bioethics Committee of the University Hospital of Murcia, in accordance with the principles of the Declaration of Helsinki, and all participants signed written informed consent.

This was a randomized, double-blind, placebo-controlled, and crossover study (Fig. 1). Before the supplementation with $\mathrm{ACJ}$, two urine-sampling periods (as controls) were used: the first was a control baseline (C-B) with minimal training loads (ECOs) and the second control (control-training: C-T) started with an increase in ECOs; both lasted 15 days. Both groups consumed ACJ or placebo for 45 days ( $200 \mathrm{~mL}$ of beverage). Ten days were utilized as the washout period without drink intake, while maintaining the training and the control diet. Subsequently, the intervention protocol was repeated, swapping the two groups according to the corresponding drink intake and maintaining their ECOs. The drink intake was 15 minutes after their training finished, to improve the bioavailability of ACJ. ${ }^{13}$ After the crossover period, the control post-treatment (CP-T) was started for the last 15 days of study without supplementation and with decreased ECOs (active recovery phase) with the objective of analyzing the post-training adaptations. Twenty-four-hour urine samples were collected at the end of each period (as shown in Fig. 1). To learn more about the study design, refer to the previously published paper. ${ }^{16}$

\subsection{Sample collection and preparation}

Twenty-four-hour urine samples were collected on the last day of each stage. They were collected in sterile and clear polystyrene pots with screw caps and were protected from light. One milliliter of the urine excreted over 24 hours was analyzed and used for the absolute calculation of the amounts of $\mathrm{F}_{4^{-}}$ NeuroPs and $\mathrm{F}_{2}$-dihomo-IsoPs excreted by all volunteers. All $\mathrm{F}_{4}$-NeuroPs and $\mathrm{F}_{2}$-dihomo-IsoPs were assayed using a previously described method. ${ }^{22}$

\subsection{Chemicals and standards}

Four $\mathrm{F}_{4}$-NeuroPs $\left(4(R S)-4-\mathrm{F}_{4 \mathrm{t}}\right.$-NeuroP, $4-\mathrm{F}_{4 \mathrm{t}}$-NeuroP, 10-epi-10$\mathrm{F}_{4 \mathrm{t}}$-NeuroP, and 10- $\mathrm{F}_{4 \mathrm{t}}-\mathrm{NeuroP}$ ) as well as four $\mathrm{F}_{2}$-dihomo-IsoPs

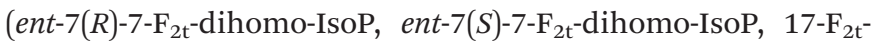
dihomo-IsoP, and 17-epi-17- $\mathrm{F}_{2 \mathrm{t}}$-dihomo-IsoP) were utilized in this experiment. Three deuterated internal standards $\left(\mathrm{d}_{4}-4(R S)\right.$ $\mathrm{F}_{4 \mathrm{t}}$-NeuroP, $\mathrm{d}_{4}-10-$ epi-10- $\mathrm{F}_{4 \mathrm{t}}-\mathrm{NeuroP}$, and $\left.\mathrm{d}_{4}-10-\mathrm{F}_{4 \mathrm{t}}-\mathrm{NeuroP}\right)$ were used for the quality control of the analyses (Fig. 2). All standards were synthesized using our published strategies. ${ }^{39-42}$ All our compounds were up to $99 \%$ pure and the structures were confirmed by microanalyses, HRMS (high resolution mass spectrometry) and full NMR (1H, 13C, HMQC). The $\beta$-glucuronidase, type $\mathrm{H} 2$, from Helix pomatia and bis-tris (bis(2-hydroxyethyl)-amino-tris (hydroxymethyl)-methane) used were purchased from Sigma-Aldrich (St Louis, MO, USA). All LC-MS grade solvents were from J.T. Baker (Phillipsburg, NJ, USA). The Strata X-AW SPE cartridges (100 mg per $3 \mathrm{~mL}$ ) were obtained from Phenomenex (Torrance, CA, USA). 


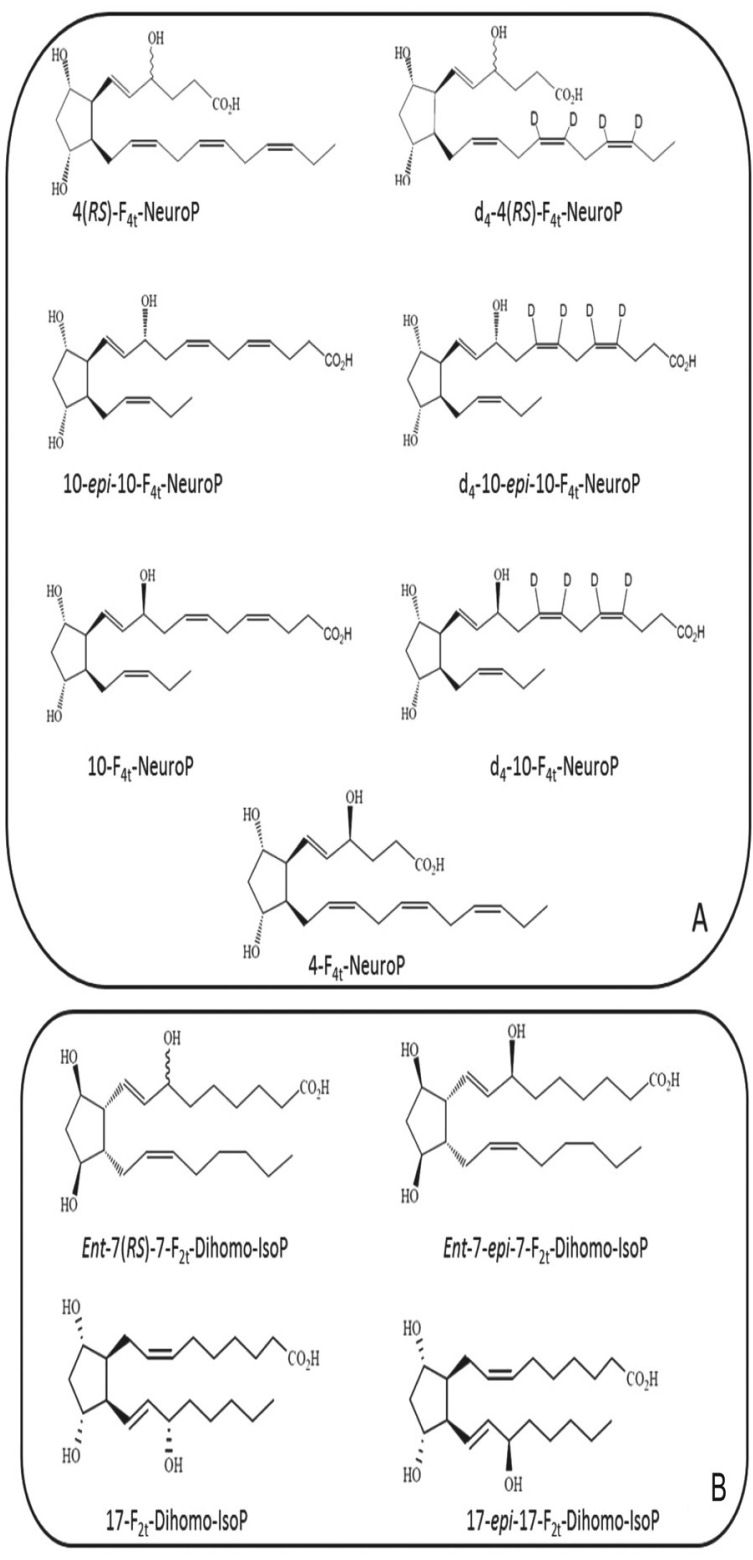

Fig. 2 Chemical structures of $F_{4}$-NeuroPs, $F_{2}$-dihomo-IsoPs, and deuterated internal standards. A: $F_{4}$-NeuroPs, $B$ : $F_{2}$-dihomo-IsoPs.

\subsection{UHPLC-QqQ-MS/MS analyses}

The separation of $\mathrm{F}_{4}$-NeuroPs and $\mathrm{F}_{2}$-dihomo-IsoPs in the urine samples was performed by ultra high pressure liquid chromatography-triple quadrupole-tandem mass spectrometry (UHPLC-QqQ-MS/MS; Agilent Technologies, Waldbronn, Germany), using the set-up described in ref. 22. Chromatographic separation was carried out on an ACQUITY $\mathrm{BEH} \mathrm{C}_{18}$ column $(2.150 \mathrm{~mm}, 1.7 \mu \mathrm{m}$ pore size) (Waters, MA, USA). The column temperatures were $6{ }^{\circ} \mathrm{C}$ (left) and $6{ }^{\circ} \mathrm{C}$ (right). The MRM was performed using the negative electrospray ionization (ESI) mode and the dwell time was $25 \mathrm{~ms}$ for all MRM transitions. The mobile phases were: (A) $\mathrm{H}_{2} \mathrm{O}$ containing $0.01 \%$ acetic acid (v/v) and (B) $\mathrm{MeOH}$ containing $0.01 \%$ acetic acid (v/v). The injection volume was $20 \mu \mathrm{L}$. The analysis time for each sample was $10.01 \mathrm{~min}$. The flow rate was $0.2 \mathrm{~mL}$ $\min ^{-1}$, using a linear gradient scheme: $(t ; \% B):(0.0 ; 60.00)$, (7.00; 70.00), (7.01; 90.00), (10.00; 90.00), (10.01; 60.00). The MS parameters fragmentor (ion optics) and collision energy were optimized for each compound. Data acquisition and processing were performed using Mass Hunter software version B.04.00 (Agilent Technologies, Waldbronn, Germany). The identification and quantification of $\mathrm{F}_{4}$-NeuroPs and $\mathrm{F}_{2}$ dihomo-IsoPs were carried out using the authentic markers previously described. ${ }^{22}$

\subsection{Statistical analyses}

Specific differences between the amounts of $\mathrm{F}_{4}$-NeuroPs and $\mathrm{F}_{2}$-dihomo-IsoPs excreted (ng per $24 \mathrm{~h}$ ) in the different stages were analyzed by Friedman's non-parametric repeated measures analysis of variance (ANOVA), since the normality and/or equal variance tests failed. When a significant difference was found in the ANOVA, a pair-wise comparison was performed using the Wilcoxon signed rank test with Bonferroni correction. A posteriori, sample size was calculated using the value $r$, calculated by $r=Z / \sqrt{ } N$, in which $Z$ is the $Z$-score that SPSS produces, and $N$ is the size of the study on which $Z$ is based. An $r$ value of $0.1,0.3$, or 0.5 was considered to show a small, moderate, or large effect, respectively. ${ }^{43}$ The data are shown as mean $\pm \mathrm{SD}$, as well as the quartiles (upper values $75 \%$, median $50 \%$, and lower values $25 \%$ ), of the $\mathrm{F}_{4}$-NeuroPs and $\mathrm{F}_{2}$-dihomo-IsoPs excreted throughout the study. Because the crossover period data of the two phases did not differ, data from both groups were pooled into one placebo or ACJ treatment. The statistical analyses were carried out using the SPSS 23.0 software package (LEAD Technologies Inc. Chicago, USA). The graphs were plotted using the Sigma Plot 12.0 software package (Systat Software, Inc. SigmaPlot for Windows).

\section{Results and discussion}

In a previous study realized in our group, we observed that urinary levels of the $\mathrm{F}_{4}$-NeuroPs and $\mathrm{F}_{2}$-dihomo-IsoPs remained constant during a short triathlon training period ( 2 weeks) at sea level. ${ }^{44}$ This study analyzed the same eight biomarkers in urine, but the present trial had a longer period (145 days) allowing us to analyze the chronic effects of exercise, as well as of the supplementation of our polyphenols-rich juice $(200 \mathrm{~mL})$ in the diet after training. As was mentioned in the introduction, during chronic training, an increase in OS products was detected and this increase can then disrupt the balance of the OS status. ${ }^{1-3}$ In athletes, an option for balancing their OS status is to strictly follow an appropriate diet in which fruit is included thanks to its antioxidant and healthpromoting properties. ${ }^{29,30}$ In addition, beverages in the world of sport are among the best food products since they can provide benefits for voluntary fluid intake, rapid fluid absorption, improvement of performance and enhanced rehydration. ${ }^{45}$

The excretion values of the lipid peroxidation products from CNS were used to compare them through of the five 
Table 4 Urinary $\mathrm{F}_{4}$-neuroprostanes and $\mathrm{F}_{2}$-dihomo-isoprostane (ng per $\left.24 \mathrm{~h}\right)^{a}$ determined throughout the assay

\begin{tabular}{|c|c|c|c|c|c|c|c|c|c|}
\hline \multirow[b]{2}{*}{ From } & \multirow[b]{2}{*}{ Analyte $^{a}$ (ng per $\left.24 \mathrm{~h}\right)$} & \multirow[b]{2}{*}{$X^{2}$} & \multirow[b]{2}{*}{ df } & \multirow[b]{2}{*}{ Sig } & \multicolumn{5}{|l|}{ Stage of study } \\
\hline & & & & & $\mathrm{C}-\mathrm{B}(n=16)$ & $\mathrm{C}-\mathrm{T}(n=16)$ & $\begin{array}{l}\text { Placebo }^{b} \\
(n=16)\end{array}$ & $\operatorname{ACJ}^{b}(n=16)$ & CP-T $(n=16)$ \\
\hline $\mathbf{\Omega 3}$ & \multicolumn{9}{|c|}{ Neuronal membrane degradation } \\
\hline \multirow[t]{2}{*}{ DHA } & 10-epi-10- $\mathrm{F}_{4 \mathrm{t}}-$ NeuroP & 11.37 & 2 & 0.003 & $4930.3 \pm 1844.4$ & $2953.2 \pm 1176.3$ & $\mathbf{4 1 3 5 . 4} \pm 1005.0$ & n.d. & n.d. \\
\hline & $10-\mathrm{F}_{4 \mathrm{t}}-\mathrm{NeuroP}$ & 20.93 & 2 & 0.000 & $2711.6 \pm 294.5$ & $1909.9 \pm 116.7$ & $891.6 \pm 372.7$ & n.d. & n.d. \\
\hline $\mathbf{\Omega 6}$ & \multicolumn{9}{|c|}{ Neuromotor system degradation } \\
\hline \multirow[t]{4}{*}{ AdA } & 17-epi-17-F ${ }_{2 \mathrm{t}}$-dihomo-IsoP & 27.14 & 4 & 0.000 & $2689.4 \pm 487.5$ & $2018.6 \pm 507.0$ & $2016.6 \pm 330.4$ & $1787.0 \pm 328.6$ & $2319.9 \pm 444.9$ \\
\hline & $17-\mathrm{F}_{2 \mathrm{t}}$-dihomo-IsoP & 24.48 & 4 & 0.000 & $3604.4 \pm 628.4$ & $2677.7 \pm 444.7$ & $2842.8 \pm 316.7$ & $2559.1 \pm 504.4$ & $2607.1 \pm 450.9$ \\
\hline & Ent-7 $(R)-7-\mathrm{F}_{2 \mathrm{t}}$-dihomo-IsoP & 22.56 & 4 & 0.000 & $4045.3 \pm 763.5$ & $3551.1 \pm 534.2$ & $3914.9 \pm 444.2$ & $\mathbf{4 0 7 0 . 2} \pm 599.5$ & $4639.7 \pm 612.8$ \\
\hline & $\begin{array}{l}\text { Ent-7-epi-7- } \mathrm{F}_{2 \mathrm{t}} \text {-dihomo- } \\
\text { IsoP }\end{array}$ & 8.80 & 4 & 0.066 & $4179.0 \pm 815.7$ & $4020.6 \pm 1115.9$ & $4216.3 \pm 629.4$ & $4813.23 \pm 1040.9$ & $4255.0 \pm 834.2$ \\
\hline
\end{tabular}

The data are shown as means \pm SD. n.d.: not detected. ${ }^{a}$ The volume of urine excreted by the volunteers was $1212.42 \pm 716.50 \mathrm{ml}$ per $24 \mathrm{~h}$, on average, in all the periods. ${ }^{b}$ Average of the two urine collections in the crossover period (Placebo/ACJ). C-B; Control Baseline, C-T; Control Training, ACJ; Aronia-Citrus Juice, CP-T; Control Post-Treatment.

stages of our clinical trial. Only six biomarkers were quantified (Table 4). Identification was confirmed according to their molecular mass, the characteristic MS/MS fragmentation product ions, and the retention time relative to the corresponding standard. The measured ions were the product ions at $m / z 152.9$ (10-epi-10- $\mathrm{F}_{4 \mathrm{t}}-\mathrm{NeuroP}$ and $\left.10-\mathrm{F}_{4 \mathrm{t}}-\mathrm{NeuroP}\right), \mathrm{m} / \mathrm{z}$ 337.1 (17- $\mathrm{F}_{2 \mathrm{t}}$-dihomo-IsoP and 17-epi-17- $\mathrm{F}_{2 \mathrm{t}}$-dihomo-IsoP), and $m / z \quad 362.2$ (ent-7(R)-7- $\mathrm{F}_{2 \mathrm{t}}$-dihomo-IsoP, ent-7(S)-7- $\mathrm{F}_{2 \mathrm{t}}$-dihomoIsoP) derived from the precursor ions $m / z 377.1$ (for NeuroPs) and $m / z 381.1$ ( $\mathrm{F}_{2 \mathrm{t}}$-dihomo-IsoP).

Our volunteers did not show representative differences through the experimental study, according to the working Group of Kinanthropometrics procedure (Table 1). The majority of our triathletes ranged from 19 to 21 years old (Table 1), belonging to the young adult period in accordance with the human life-stages. According to our current knowledge ${ }^{46}$ this life-stage is ideal for quantification of these specific markers for DHA and AdA peroxidation $\left(\mathrm{F}_{4}-\mathrm{NeuroPs}\right.$ and $\mathrm{F}_{2}$-dihomo-IsoPs), since in sedentary and healthy young adults we detected low amounts of oxidative damage biomarkers. Thereby, the evaluation in this group indicated a realistic demonstration of the effects due to triathlon training and supplementation of our ACJ in the diet on lipid peroxidation from CNS.

The information that follows below may open new avenues for research of the possible roles of polyphenols and other bioactive compounds from a polyphenols-rich beverage-ACJ-on oxidative damage to lipids, essential constituent of nervous tissue (conceived in a chronic triathlon training context using the objective load scale (ECOs)), thanks to the properties of the phenolic compounds to scavenge free radicals in vivo or to activate redox antioxidant pathways in the human body. ${ }^{16,33}$ It must be taken into account that the biomarkers used in this study are oxidative products deriving from the radical attack on adrenic acid (AdA, C22:4 n-6) or docosahexaenoic acid (DHA, C22:6 n-3) and are good prognostic markers for the evolution of oxidative stress linked to the CNS, ${ }^{22,44}$ like isoprostanes or DNA oxidation catabolites are at the systemic level. ${ }^{16,33,38}$

\section{1 $\mathbf{F}_{2}$-dihomo-isoprostanes}

The $\mathrm{F}_{2}$-dihomo-IsoPs are specific markers for free radicalinduced AdA peroxidation, being potential markers of free radical damage to myelin in the human brain. ${ }^{18}$ For example, in cerebrospinal fluid, the $\mathrm{F}_{2}$-dihomo-IsoPs levels were associated with some neuropsychological symptoms of Alzheimer's disease. $^{47}$ De Felice et al. published ${ }^{23}$ that the plasma $\mathrm{F}_{2}$ dihomo-IsoPs were involved in the pathogenesis of Rett syndrome. In this assay, the urinary biomarkers derived from AdA were detected in all samples during the whole period of the study, and ranged from $\sim 1787$ to $\sim 4813 \mathrm{ng}$ per $24 \mathrm{~h}$ (Table 4 ). The two $\mathrm{F}_{2}$-dihomo-IsoP metabolites of the 17-series showed significant changes (Table 4); the values decreased with the increase of ECOs training and continued to decline during the ACJ intake. Particularly, 17-epi-17- $\mathrm{F}_{2 \mathrm{t}}$-dihomo-IsoP differed significantly in the C-B stage compared to in the C-T $(Z=-2.783$, $P=0.005, r=0.695)$, placebo $(Z=-3.124, P=0.002, r=0.781)$, and ACJ stages $(Z=-3.408, P=0.001, r=0.852)$. The excretion of $17-\mathrm{F}_{2 \mathrm{t}}$-dihomo-IsoP reached its highest value in the $\mathrm{C}-\mathrm{B}$ stage. The Bonferroni correction of the results from the Wilcoxon test gave $P<0.005$, showing that the C-B stage value was statistically higher than those from placebo $(Z=-3.124$, $P=0.002, r=0.781)$, ACJ $(Z=-3.067, P=0.002, r=0.766)$, and CP-T stages $(Z=-3.181, P=0.001, r=0.795)$ (Fig. 3). Therefore, our results demonstrated that the $\mathrm{F}_{2}$-dihomo-IsoPs values showed significant changes owing to the increase or decrease of the training loads, as well as the influence depending on the time (acute or chronic). The OS elicits different responses depending on the type of the organ tissue and its endogenous antioxidant levels upon acute and chronic exercise. ${ }^{3}$ In fact, regular aerobic, moderate training or physical activity programs could increase the resistance against OS to promote antioxidant capacity in the brain. ${ }^{3}$ Highlighting also that our athletes have no influence according to their range age, since a study found that there were no significant differences in levels of ent-7(R)-7- $\mathrm{F}_{2 \mathrm{t}}$-dihomo-IsoP, ent-7-epi-7- $\mathrm{F}_{2 \mathrm{t}}{ }^{-}$ dihomo-IsoP, 17- $\mathrm{F}_{2 \mathrm{t}}$-dihomo-IsoP, and 17-epi-17- $\mathrm{F}_{2 \mathrm{t}}$-dihomo- 

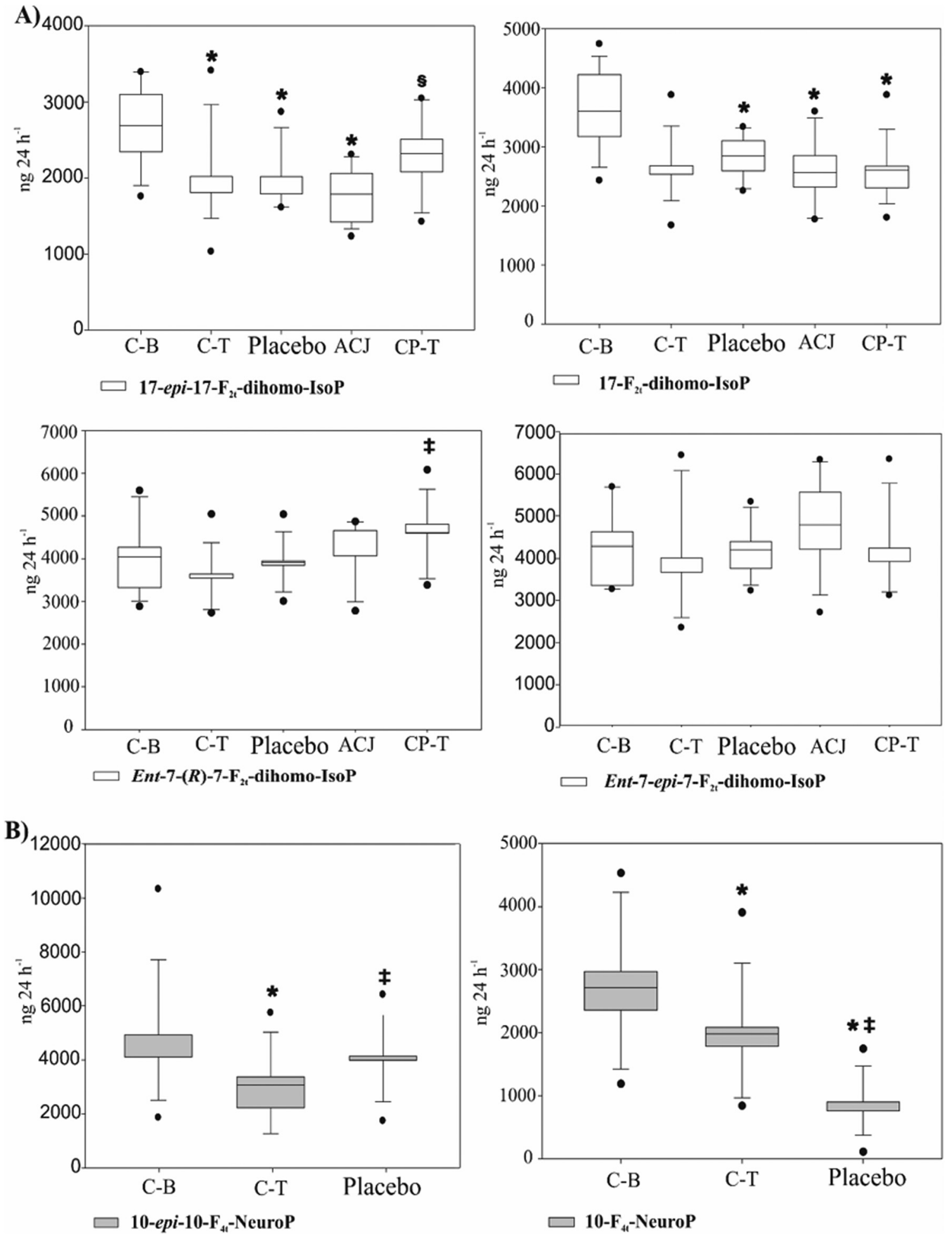

Fig. 3 Box plots with quartiles (upper values $75 \%$, median $50 \%$, and lower values $25 \%$ ) of the (A) $F_{2}$-dihomo-IsoPs and (B) $F_{4}-\mathrm{NeuroPs}$ in $24 \mathrm{~h}^{-1}$ urine throughout the study (ng per $24 \mathrm{~h}$ ). - Outlier data are shown. *: shows a significant difference compared to the C-B stage, $\S$ : shows a significant difference compared to the ACJ stage and $\uparrow$ : shows a significant difference compared to the $\mathrm{C}$ - $\mathrm{T}$ stage. Significant $P$-values are shown according to post hoc analysis with Wilcoxon signed-rank tests (with a Bonferroni correction $P<0.005$, for $\mathrm{F}_{2}$-dihomo-IsoPs and $P<0.016$, for $\mathrm{F}_{4}$ NeuroPs). Abbreviations: C-B; Control Baseline, C-T; Control Training, ACJ; Aronia-Citrus Juice, CP-T; Control Post-Treatment. 
IsoP in sedentary and healthy volunteers between the ages of 13 and 35 years. $^{46}$

Otherwise, the Friedman test showed a significant difference in the ent-7-(R)-7- $\mathrm{F}_{2 \mathrm{t}}$-dihomo-IsoP values (Table 4 ), and also a significant increase in the CP-T stage compared with in the C-T stage. In the CP-T stage, the training load was decreased around 50\% after 115 days with high load training (1008 \pm 105 ECOs). Post hoc analysis with the Wilcoxon signedrank test showed that values were higher in the CP-T stage (Fig. 3), although only the C-T stage $(Z=-3.389, P=0.001, r=$ $0.847)$ differed significantly with the Bonferroni correction $(P<$ 0.005). This result indicates that an acute decrease of training loads after a chronic exercise programme may stimulate an adaptation response where this oxidative product deriving from radical attack on AdA (ent-7 $(R S)-7-\mathrm{F}_{2 \mathrm{t}}$-dihomo-IsoP) could play a role in this adaptation post-training, although typically the $\mathrm{F}_{2}$-dihomo-IsoPs provide a relatively selective insight into oxidative damage to myelin since they are the oxidative products deriving from radical attack on AdA. These markers are also considered to reflect cerebral white matter injury; ${ }^{48}$ however, we should also remember that AdA is present in other organs, like the kidney and adrenal glands. ${ }^{18,49}$ Thereby, physical exercise effects on OS from kidney and adrenal glands could also reflect similar results. Besides, a previous study reflected that the urinary levels of $\mathrm{F}_{2}$-IsoP decreased with chronic exercise in most of the cases and chronic exercise may rarely result in increased urine $\mathrm{F}_{2}$-IsoP levels, ${ }^{48}$ while some studies have supported no changes. Our results are consistent with the three changes that were mentioned by Nikolaidis et $a l .{ }^{50}$ in their review, since any change in the ent-7-epi-7- $\mathrm{F}_{2 \mathrm{t}^{-}}$ dihomo-IsoP values was also observed ${ }^{18}$ remaining at constant levels throughout the study with no statistical differences.

Regarding the possible role of the compounds from our juice on the lipid peroxidation from AdA (whatever the current physiological origin: brain white matter, adrenal gland or kidney), the 17-epi-17- $\mathrm{F}_{2 \mathrm{t}}$-dihomo-IsoP in the ACJ stage was significantly lower than the CP-T stage values $(Z=-3.013, P=$ $0.003, r=0.753$; Fig. 3). From our point of view, this significant difference perhaps is due to over-activation of the steroid biosynthesis pathway in the particular case of citrus juices, ${ }^{51}$ since this pathway is mainly located in the adrenal glands and gonads as well as within the nervous system. There is evidence of neurotrophic and neuroprotective effects on the CNS involving a steroid mechanism, for example, the progesterone has been linked with a decreased of the amount of LPP. ${ }^{52}$ A steroid conjugate from progesterone (17-hydroxyprogesterone) was identified as a significant metabolite after the citrus juice intake, ${ }^{51}$ suggesting a possible role in OS status. Another explanation is that due to food biomarkers discovered after the ingestion of ACJ in healthy volunteers, proline betaine, ferulic acid, and two mercapturate derivatives, ${ }^{17}$ they may be related with the decrease of 17-epi-17- $\mathrm{F}_{2 \mathrm{t}}$-dihomo-IsoP levels in combination with the training sessions. For example, the proline betaine (specific and sensitive marker of citrus fruit intake) had a lowering effect on plasma homocysteine concentration in healthy volunteers. ${ }^{53}$ Lowering plasma homocysteine levels has been related with lowered OS, conversely if this amino acid increases its levels it can lead to prooxidative activity, agerelated cognitive impairment, and neurodegenerative and cerebrovascular disease. ${ }^{54}$ In addition, ferulic acid also provides protection against lipid peroxidation and prevents attacks to the membrane, acting as a potential antioxidant due to its structural characteristics, the presence of electron donating groups on the benzene ring and its carboxylic acid group. ${ }^{55}$ In biological models, the ferulic acid showed a role as an inhibitor or disaggregating agent of amyloid structure, suggesting a positive effect in the first steps to trigger Alzheimer's disease. ${ }^{56}$ Alzheimer's disease has been related with the increase of $\mathrm{F}_{2}$-dihomo-IsoPs levels. ${ }^{18}$ On the other hand, it is noteworthy that ACJ, besides its phytochemicals, provides other compounds such as vitamins and minerals that appear to have or help antioxidative activities providing health benefits. The vitamin $\mathrm{C}$ from the mixture (from citrus to Aronia) is a representative compound. ${ }^{32}$ Ascorbic acid (vitamin C) is an electron donor and reducing agent, so it prevents the oxidation of biomolecules. ${ }^{57}$ Ascorbic acid is accumulated in adrenal glands and the central nervous system, indicative of the importance of ascorbate function in the CNS, even with low plasma levels. ${ }^{58}$ Besides its function as a reactive oxygen species scavenger, it also helps to restore other substances with antioxidant properties, such as alpha-tocopherol (vitamin E) or glutathione (antioxidant in plants). ${ }^{57}$ There is no conclusive data regarding the anti-oxidative effects related to mineral intake from Aronia and/or citrus, although orange juice consumption has been shown to enhance the absorption of minerals (iron, aluminum, calcium, zinc, and selenium) from the diet. ${ }^{59}$ Besides, we found that in animal models the hesperidin intake (a monomethylated flavanone found abundantly in oranges) due to its antioxidant and anti-inflammatory properties showed protective effects on bone mineral density. ${ }^{60}$ The minerals in vivo are involved in the production of free radicals, since they can accelerate or delay the oxidative stress and neurodegeneration occurring in the CNS. ${ }^{58}$ Therefore, minerals and vitamins from our ACJ were maybe involved in the lipid peroxidation pathways for this result.

Nonetheless, further research is needed on the correlation of potential beneficial effects of polyphenols-rich dietary supplements and their particular mechanisms of action of each compound on its own or in conjunction with others on the markers of central nervous system degradation in athletes, although some experimental studies have indicated positive biological effects of polyphenols-rich dietary supplements in athletes. 5,9,13,61,62 Thus, we are developing further research to clarify the positive influence that the intake of functional fruit juices and polyphenols could have in athletes. ${ }^{16}$

\section{$3.2 \quad$ F $_{4}$-neuroprostanes}

The $\mathrm{F}_{4}$-NeuroPs originate from the free radical-catalysed peroxidation of DHA-an essential constituent of nervous tissue that is highly enriched in neurons and highly susceptible to oxidation. ${ }^{21}$ Looking at our findings, we note a possible effect of $\mathrm{ACJ}$ at the neuronal level, since $10-$ epi-10- $\mathrm{F}_{4 \mathrm{t}}-\mathrm{NeuroP}$ and 
$10-\mathrm{F}_{4 \mathrm{t}}$-NeuroP were not detected during the intake period compared to in the placebo stage. In the C-T stage, two $\mathrm{F}_{4}$-NeuroPs (10-epi-10-F 4 -NeuroP $(Z=-2.845, P=0.004, r=0.711)$ and 10 $\mathrm{F}_{4 \mathrm{t}}$-NeuroP $\left.(Z=-2.499, P=0.012, r=0.624)\right)$ showed a decrease before the crossover intake of the beverages (placebo or ACJ) (Fig. 3). The $10-\mathrm{F}_{4 \mathrm{t}}$-NeuroP values continued to decline significantly in the placebo stage $(Z=-3.130, P=0.002, r=0.782)$ (Fig. 3). During the ACJ and CP-T stages, these $\mathrm{F}_{4}$-NeuroPs were not detected (Table 4). The decline of the excretion of the NeuroPs in our study could partially be attributed to the ingestion of bioactive compounds found in our polyphenols-rich juice. There is evidence showing that citrus fruits intake could alter the OS of the $\mathrm{CNS}^{7}$ and, particularly, that polyphenols may alter brain function at three locations: outside the CNS (for instance, by improving cerebral blood flow or by modulating signaling pathways from peripheral organs to the brain), at the blood-brain barrier (e.g., by altering multi-drug-resistant protein-dependent influx and efflux mechanisms of various biomolecules), and inside the CNS (e.g., by directly modifying the activity of neurons and glial cells). In addition, citrus fruits, which are rich and abundant sources of hesperidin and other polyphenols, are promising for the development of general foodbased neuroprotection and "brain foods". ${ }^{15}$ A recent review gathered evidence about the neuroprotective actions of the flavonoids mentioned that may influence the survival cascade and transcription factors by modulating the redox potential of neurons and glia. In vivo activities of flavonoids in the brain remain to be elucidated, but have shown potential functions against oxidative damage, ${ }^{63}$ as has been shown in this study.

The health effects of polyphenols depend on the amount consumed and their bioavailability. The bioavailability is a key aspect to exert antioxidant activity in humans, since many polyphenols have a scarce bioavailability and are extensively metabolized. ${ }^{64}$ According to our previous study, the bioavailability of flavanones from ACJ intake increased in the triathletes, suggesting that over-activation of the microbiota and intestinal motility were caused by physical exercise, helping to increase the bioavailability of the compounds in the ACJ. ${ }^{13}$ The results obtained in this study with ACJ supplementation (one serving, $200 \mathrm{~mL}$ ), which was adjusted to the normal diet of our athletes (the intake always being around 15 minutes after training for 45 days) suggest an effect of the ACJ due to the combination with the physical exercise. This could be based on the physiological changes that may re-establish colonic motility after exercise, when blood flow is restored, allowing maximum exposure and absorption of nutrients including polyphenols and thus, the increase in the flavonoids bioavailability. ${ }^{64}$ In support of the above affirmation, Gomez-Pinilla ${ }^{8}$ mentioned that the combination of polyphenols intake and physical activity can deliver more beneficial effects than intervention alone or the mixed effects of exercise. For example, a study in athletes showed that the increase of the intake of anthocyanins can limit exercise-induced oxidative damage to red blood cells, most probably by enhancing the endogenous antioxidant defense system. These athletes consumed $150 \mathrm{~mL}$ of chokeberry juice daily-providing $23 \mathrm{mg}$ per $100 \mathrm{~mL}$ antho- cyanin-for a period of one month. ${ }^{62}$ Other nutritional interventions in athletes also showed the protective effect against OS induced by the consumption of polyphenols from grape extract (400 mg per day). ${ }^{61}$ Furthermore, berry extracts could have effects associated with their ability to maintain metabolic homeostasis, thus protecting membranes from lipid peroxidation and affecting synaptic plasticity. ${ }^{65}$ In vitro and animal models have proved the beneficial effects of polyphenols on exercise-induced OS, muscle damage and exercise performance, but in human studies further research is required for the better assessment of their benefits. ${ }^{4}$ Currently, the mechanisms by which physical exercise exerts its effects in the brain remain largely unknown, although researchers have provided promising evidence about physical exercise-induced outcomes for several prevalent neurological and psychiatric conditions (CNS) ${ }^{66}$ The reduction of oxidative stress has provided possible evidence to suggest the positive effects on CNS health. ${ }^{3,66}$ Thus, our study provides evidence of the effect of the intake of ACJ (rich in polyphenols) during a training period with regard to the decrease of the NeuroPs values, suggesting a potential positive effect on the nervous system during training.

Another interesting point besides the apparent absence of 10-epi-10- $\mathrm{F}_{4 \mathrm{t}}-\mathrm{NeuroP}$ and $10-\mathrm{F}_{4 \mathrm{t}}-\mathrm{NeuroP}$ in the ACJ stage was the significant changes in the values of these NeuroPs during the stages in which they were detected (C-B, C-T, and placebo stages) (Table 4). The excretion of these metabolites tended to decrease, as we could observe for $10-\mathrm{F}_{4 \mathrm{t}}-\mathrm{NeuroP}$ during the study, but in the placebo stage 10-epi-10- $\mathrm{F}_{4 \mathrm{t}}-\mathrm{NeuroP}$ exhibited a significant increase $(Z=-2.543, P=0.011, r=0.635)$ compared with in the $\mathrm{C}-\mathrm{T}$ stage, but returned to previous values in the C-B stage. This behavior of the stereoisomers can depend on different mechanisms, but the precise roles of these isomers in vivo have not been elucidated yet. In the urine analysis of the systemic neuroprostane-like compounds (isoprostane, IsoPs) formed in vivo via the non-enzymatic, free radicalinitiated peroxidation of polyunsaturated fatty acids, it is important to consider that these molecules are not only excreted in the original form since they are extensively metabolized in the liver, producing a biotransformation of the metabolites. ${ }^{67}$ For example, in a study of smokers, all IsoPs are equally increased by any source of OS (e.g., smoking), but some are more efficiently metabolized so that their determined concentrations appear less affected by variations in oxidant levels. ${ }^{68}$ This would mean that highly metabolized IsoPs appear less correlated with smoking than less-metabolized IsoPs. Another possibility was that exposure to different types of oxidants may affect the mechanisms that create IsoPs, thereby affecting their distribution. In our study, the closest relationship was between chronic physical exercise and the metabolite 10-epi-10- $\mathrm{F}_{4 \mathrm{t}}$-NeuroP.

Finally, two $\mathrm{F}_{4 \mathrm{t}}$-NeuroPs $\left(4-(R S)-4-\mathrm{F}_{4 \mathrm{t}^{-N}}\right.$ NeuroP and $4-\mathrm{F}_{4 \mathrm{t}^{-}}$ NeuroP) were analyzed in this study, but they were below the limit of detection/quantification. Therefore, these data are not shown. In previous work, $4-(R S)-\mathrm{F}_{4 \mathrm{t}}-$ NeuroP and $4 \mathrm{~F}_{4 \mathrm{t}}-$ NeuroP were also not detected. ${ }^{22}$ In addition, another mediator of oxidative stress from omega-3 fatty acid, docosapentaenoic acid 
( $4-\mathrm{F}_{3 \mathrm{t}}$ NeuroP), was only detected in $22.22 \%$ of the 45 young adults volunteers. ${ }^{46}$ Thus, the latest data continue to support the idea that the NeuroPs do not appear to be specific biomarkers in healthy or sedentary volunteers.

\section{Conclusions}

The $\mathrm{F}_{4}$-NeuroPs 10 -epi-10- $\mathrm{F}_{4 \mathrm{t}}$-NeuroP and $10-\mathrm{F}_{4 \mathrm{t}}-\mathrm{NeuroP}$ were not detected after the consumption of ACJ. The changes in the excretion values of these biomarkers suggest health benefits that could be attributed to the ingestion of bioactive compounds that include partial co-responsibility of flavonoids and others phenolic found in ACJ on the oxidative status neuronal membrane. The changes in the excretion of $17-e p i-17-\mathrm{F}_{2 \mathrm{t}^{-}}$ dihomo-IsoP show a positive connection between physical exercise and ACJ intake, suggesting that the combination of polyphenols intake and physical activity can deliver beneficial effects on the neuromotor system. The physical exercise by itself was also able to exert different responses depending on the increase $\left(17-\mathrm{F}_{2 \mathrm{t}}\right.$-dihomo-IsoP) or the decrease (ent-7- $(R S)$ $7-\mathrm{F}_{2 \mathrm{t}}$-dihomo-IsoP) of the training loads. Thus, the chronic intake of one serving of ACJ rich in polyphenols $(200 \mathrm{~mL}$, adjusted to the diet) and adequate training influenced the OS of the CNS in young adult triathletes, which will help to elucidate novel interactions and mechanisms between excretion of lipid peroxidation metabolites, supplementation of polyphenols-rich juice in the diet and physical exercise during a training season. These actions and mechanisms may be linked to the properties of polyphenols to scavenge free radicals in vivo themselves or to activate redox antioxidant pathways in the human body.

\section{Conflict of interest}

The authors declare that they have no conflict of interest.

\section{Acknowledgements}

This study was supported by the project AGL2011-23690 (CICYT) (Spanish Ministry of Economy and Competitiveness). This work has been partially funded by the "Fundación Séneca de la Región de Murcia” Grupo de Excelencia 19900/GERM/15. LAGF was granted a pre-doctoral FPI fellowship (BES2012060185) by the Spanish government. The authors are grateful to the University of Alicante for its collaboration. We are grateful to Dr David Walker (native English speaker) and Dr Pablo Rodríguez, for their reviews of the English grammar and style of the current report.

\section{Notes and references}

1 T. T. Peternelj and J. S. Coombes, Antioxidant supplementation during exercise training: beneficial or detrimental?, Sports Med., 2011, 41, 1043-1069.
2 R. T. Mankowski, S. D. Anton, T. W. Buford and C. Leeuwenburgh, Dietary Antioxidants as Modifiers of Physiologic Adaptations to Exercise, Med. Sci. Sports Exercise, 2015, 47, 1857-1868.

3 D. Camiletti-Moiron, V. A. Aparicio, P. Aranda and Z. Radak, Does exercise reduce brain oxidative stress? A systematic review, Scand. J. Med. Sci. Sports, 2013, 23, e202e212.

4 M. Malaguti, C. Angeloni and S. Hrelia, Polyphenols in exercise performance and prevention of exercise-induced muscle damage, Oxid. Med. Cell. Longevity, 2013, 2013, 825928 .

5 D. Del Rio, A. Rodriguez-Mateos, J. P. Spencer, M. Tognolini, G. Borges and A. Crozier, Dietary (poly)phenolics in human health: structures, bioavailability, and evidence of protective effects against chronic diseases, Antioxid. Redox Signal., 2013, 18, 1818-1892.

6 F. Gomez-Pinilla and T. T. Nguyen, Natural mood foods: the actions of polyphenols against psychiatric and cognitive disorders, Nutr. Neurosci., 2012, 15, 127-133.

7 S. Schaffer and B. Halliwell, Do polyphenols enter the brain and does it matter? Some theoretical and practical considerations, Genes Nutr., 2012, 7, 99-109.

8 F. Gomez-Pinilla, The combined effects of exercise and foods in preventing neurological and cognitive disorders, Prev. Med., 2011, 52(Suppl 1), S75-S80.

9 K. H. Myburgh, Polyphenol supplementation: benefits for exercise performance or oxidative stress?, Sports Med., 2014, 44(Suppl 1), S57-S70.

10 A. Gil-Izquierdo, M. I. Gil, F. A. Tomás-Barberán and F. Ferreres, Influence of Industrial Processing on Orange Juice Flavanone Solubility and Transformation to Chalcones under Gastrointestinal Conditions, J. Agric. Food Chem., 2003, 51, 3024-3028.

11 C. Manach, C. Morand, A. Gil-Izquierdo, C. BouteloupDemange and C. Remesy, Bioavailability in humans of the flavanones hesperidin and narirutin after the ingestion of two doses of orange juice, Eur. J. Clin. Nutr., 2003, 57, 235242.

12 V. Habauzit, S. M. Sacco, A. Gil-Izquierdo, A. Trzeciakiewicz, C. Morand, D. Barron, S. Pinaud, E. Offord and M. N. Horcajada, Differential effects of two citrus flavanones on bone quality in senescent male rats in relation to their bioavailability and metabolism, Bone, 2011, 49, 1108-1116.

13 S. Medina, R. Domínguez-Perles, C. García-Viguera, R. Cejuela-Anta, J. M. Martínez-Sanz, F. Ferreres and A. GilIzquierdo, Physical activity increases the bioavailability of flavanones after dietary aronia-citrus juice intake in triathletes, Food Chem., 2012, 135, 2133-2137.

14 P. N. Denev, C. G. Kratchanov, M. Ciz, A. Lojek and M. G. Kratchanova, Bioavailability and antioxidant activity of black chokeberry (Aronia melanocarpa) polyphenols: in vitro and in vivo evidences and possible mechanisms of action: A review, Compr. Rev. Food Sci. Food Saf., 2012, 11, 471-489. 
15 S. L. Hwang, P. H. Shih and G. C. Yen, Neuroprotective effects of citrus flavonoids, J. Agric. Food Chem., 2012, 60, 877-885.

16 L. A. Garcia-Flores, S. Medina, R. Cejuela-Anta, J. M. Martinez-Sanz, A. Abellan, H.-G. Genieser, F. Ferreres and A. Gil-Izquierdo, DNA catabolites in triathletes: effects of supplementation with an aronia-citrus juice (polyphenols-rich juice), Food Funct., 2016, 7, 2084-2093.

17 R. Llorach, S. Medina, C. García-Viguera, P. Zafrilla, J. Abellán, O. Jauregui, F. A. Tomás-Barberán, A. GilIzquierdo and C. Andrés-Lacueva, Discovery of human urinary biomarkers of aronia-citrus juice intake by HPLC-qTOF-based metabolomic approach, Electrophoresis, 2014, 35, 1599-1606.

18 M. VanRollins, R. L. Woltjer, H. Yin, J. D. Morrow and T. J. Montine, F2-dihomo-isoprostanes arise from free radical attack on adrenic acid, J. Lipid Res., 2008, 49, 995-1005.

19 J. M. Galano, E. Mas, A. Barden, T. A. Mori, C. Signorini, C. De Felice, A. Barrett, C. Opere, E. Pinot, E. Schwedhelm, R. Benndorf, J. Roy, J. Y. Le Guennec, C. Oger and T. Durand, Isoprostanes and neuroprostanes: total synthesis, biological activity and biomarkers of oxidative stress in humans, Prostaglandins Other Lipid Mediat., 2013, 107, 95-102.

20 L. J. Roberts 2nd, T. J. Montine, W. R. Markesbery, A. R. Tapper, P. Hardy, S. Chemtob, W. D. Dettbarn and J. D. Morrow, Formation of isoprostane-like compounds (neuroprostanes) in vivo from docosahexaenoic acid, J. Biol. Chem., 1998, 273, 13605-13612.

21 J. Nourooz-Zadeh, E. H. Liu, B. Yhlen, E. E. Anggard and B. Halliwell, F4-isoprostanes as specific marker of docosahexaenoic acid peroxidation in Alzheimer's disease, J. Neurochem., 1999, 72, 734-740.

22 S. Medina, I. D. Miguel-Elízaga, C. Oger, J.-M. Galano, T. Durand, M. Martínez-Villanueva, M. L. G.-D. Castillo, I. Villegas-Martínez, F. Ferreres, P. Martínez-Hernández and Á. Gil-Izquierdo, Dihomo-isoprostanes-nonenzymatic metabolites of AdA-are higher in epileptic patients compared to healthy individuals by a new ultrahigh pressure liquid chromatography-triple quadrupole-tandem mass spectrometry method, Free Radical Biol. Med., 2015, 79, 154-163.

23 C. De Felice, C. Signorini, T. Durand, C. Oger, A. Guy, V. Bultel-Ponce, J. M. Galano, L. Ciccoli, S. Leoncini, M. D'Esposito, S. Filosa, A. Pecorelli, G. Valacchi and J. Hayek, F2-dihomo-isoprostanes as potential early biomarkers of lipid oxidative damage in Rett syndrome, J. Lipid Res., 2011, 52, 2287-2297.

24 E. Miller, A. Morel, L. Saso and J. Saluk, Isoprostanes and neuroprostanes as biomarkers of oxidative stress in neurodegenerative diseases, Oxid. Med. Cell. Longevity, 2014, 2014, 572491.

25 R. T. Withers, N. P. Craig, P. C. Bourdon and K. I. Norton, Relative body fat and anthropometric prediction of body density of male athletes, Eur. J. Appl. Physiol. Occup. Physiol., 1987, 56, 191-200.
26 R. C. Lee, Z. Wang, M. Heo, R. Ross, I. Janssen and S. B. Heymsfield, Total-body skeletal muscle mass: development and cross-validation of anthropometric prediction models, Am. J. Clin. Nutr., 2000, 72, 796-803.

27 A Report of the Panel on Macronutrients; Subcommittees on Upper Reference Levels of Nutrients and Interpretation and Uses of Dietary Reference Intakes; Standing Committee on the Scientific Evaluation of Dietary Reference Intakes; Food and Nutrition Board; Institute of Medicine. Medicine, National Academies Press, Washington, DC, 2005, DOI: 10.17226/10490.

28 B. E. Ainsworth, W. L. Haskell, M. C. Whitt, M. L. Irwin, A. M. Swartz, S. J. Strath, W. L. O’Brien, D. R. Bassett Jr., K. H. Schmitz, P. O. Emplaincourt, D. R. Jacobs Jr. and A. S. Leon, Compendium of physical activities: an update of activity codes and MET intensities, Med. Sci. Sports Exer., 2000, 32, S498-S504.

29 A. E. Jeukendrup, R. L. P. G. Jentjens and L. Moseley, Nutritional considerations in triathlon, Sports Med., 2005, 35, 163-181.

30 J. M. Martínez-Sanz, U. O. Aritz and J. Mielgo-Ayuso, Necesidades energéticas, hídricas y nutricionales en el deporte, Eur. J. Human Mov., 2010, 30, 37-52.

31 P. I. Salvador, G. A. Puchal, M. C. Vila, M. Miserachs and M. Illan, Entrevista dietética: herramientas útiles para la recogida de datos, Rev. Med. Univ. Navarra, 2006, 50, 46-55.

32 E. Gonzalez-Molina, D. A. Moreno and C. Garcia-Viguera, Aronia-enriched lemon juice: a new highly antioxidant beverage, J. Agric. Food Chem., 2008, 56, 11327-11333.

33 J. Bernabé, J. Mulero, B. Cerdá, C. García-Viguera, D. A. Moreno, S. Parra, F. Avilés, A. Gil-Izquierdo, J. Abellán and P. Zafrilla, Effects of a citrus based juice on biomarkers of oxidative stress in metabolic syndrome patients, J. Funct. Foods, 2013, 5, 1031-1038.

34 R. Cejuela Anta and J. Esteve Lanao, Training load quantification in triathlon, J. Hum. Sport Exerc., 2011, 6, 218-232.

35 J. Borresen and M. I. Lambert, The quantification of training load, the training response and the effect on performance, Sports Med., 2009, 39, 779-795.

36 J. J. Saugy, L. Schmitt, R. Cejuela, R. Faiss, A. Hauser, J. P. Wehrlin, B. Rudaz, A. Delessert, N. Robinson and G. P. Millet, Comparison of "Live High-Train Low" in normobaric versus hypobaric hypoxia, PLoS One, 2014, 9, e114418.

37 A. Lucia, J. Esteve-Lanao, J. Olivan, F. Gomez-Gallego, A. F. San Juan, C. Santiago, M. Perez, C. Chamorro-Vina and C. Foster, Physiological characteristics of the best Eritrean runners-exceptional running economy, Appl. Physiol., Nutr., Metab., 2006, 31, 530-540.

38 S. Medina, R. Dominguez-Perles, R. Cejuela-Anta, D. Villano, J. M. Martinez-Sanz, P. Gil, C. Garcia-Viguera, F. Ferreres, J. I. Gil and A. Gil-Izquierdo, Assessment of oxidative stress markers and prostaglandins after chronic training of triathletes, Prostaglandins Other Lipid Mediat., 2012, 99, 79-86.

39 A. Guy, C. Oger, J. Heppekausen, C. Signorini, C. De Felice, A. Furstner, T. Durand and J. M. Galano, Oxygenated 
metabolites of n-3 polyunsaturated fatty acids as potential oxidative stress biomarkers: total synthesis of 8-F3t-IsoP, 10-F4t-NeuroP and [D4]-10-F4t-NeuroP, Chemistry, 2014, 20, 6374-6380.

40 T. Durand, A. Guy, O. Henry, A. Roland, S. Bernad, S. El Fangour, J. P. Vidal and J. C. Rossi, Total syntheses of iso-, neuro- and phytoprostanes: new insight in lipid chemistry, Chem. Phys. Lipids, 2004, 128, 15-33.

41 C. Oger, V. Bultel-Ponce, A. Guy, L. Balas, J. C. Rossi, T. Durand and J. M. Galano, The handy use of Brown's P2Ni catalyst for a skipped diyne deuteration: application to the synthesis of a [D4]-labeled F4t-neuroprostane, Chemistry, 2010, 16, 13976-13980.

42 C. Oger, V. Bultel-Poncé, A. Guy, T. Durand and J.-M. Galano, Total Synthesis of Isoprostanes Derived from adrenic acid and EPA, Eur. J. Org. Chem., 2012, 2012, 26212634.

43 A. Field and G. Hole, How to Design and Report Experiments, SAGE Publications, 2002.

44 L. A. Garcia-Flores, S. Medina, R. Cejuela, J. M. MartinezSanz, C. Oger, J. M. Galano, T. Durand, T. Casas-Pina, P. Martinez-Hernandez, F. Ferreres and A. Gil-Izquierdo, Assessment of oxidative stress biomarkers - neuroprostanes and dihomo-isoprostanes - in the urine of elite triathletes after two weeks of moderate-altitude training, Free Radical Res., 2016, 50, 485-494.

45 R. Murray and J. R. Stofan, in Sports Drinks, Basic science and practical Aspects, ed. R. Murray and J. Maughan, CRC press LLC, Boca Raton, FL, USA, 2001, ch. 8, pp. 197-223.

46 L. A. García-Flores, S. Medina, P. Martínez-Hernández, C. Oger, J.-M. Galano, T. Durand, T. Casas-Pina and A. GilIzquierdo, Snapshot situation of degradation of the nervous system biomarkers -neuroprostane and dihomoisoprostanes- from infancy to elderly, ACS Neurochem., 2016.

47 H. C. Kuo, H. C. Yen, C. C. Huang, W. C. Hsu, H. J. Wei and C. L. Lin, Cerebrospinal fluid biomarkers for neuropsychological symptoms in early stage of late-onset Alzheimer's disease, Int. J. Neurosci., 2014, 125, 747-754.

48 T. Durand, C. De Felice, C. Signorini, C. Oger, V. BultelPonce, A. Guy, J. M. Galano, S. Leoncini, L. Ciccoli, A. Pecorelli, G. Valacchi and J. Hayek, F(2)-Dihomo-isoprostanes and brain white matter damage in stage 1 Rett syndrome, Biochimie, 2013, 95, 86-90.

49 C. De Felice, L. Ciccoli, S. Leoncini, C. Signorini, M. Rossi, L. Vannuccini, G. Guazzi, G. Latini, M. Comporti, G. Valacchi and J. Hayek, Systemic oxidative stress in classic Rett syndrome, Free Radicals Biol. Med., 2009, 47, 440-448.

50 M. G. Nikolaidis, A. Kyparos and I. S. Vrabas, F(2)-isoprostane formation, measurement and interpretation: the role of exercise, Prog. Lipid Res., 2011, 50, 89-103.

51 S. Medina, F. Ferreres, C. García-Viguera, M. N. Horcajada, J. Orduna, M. Savirón, G. Zurek, J. M. Martínez-Sanz, J. I. Gil and A. Gil-Izquierdo, Non-targeted metabolomic approach reveals urinary metabolites linked to steroid bio- synthesis pathway after ingestion of citrus juice, Food Chem., 2013, 136, 938-946.

52 M. Schumacher, Y. Akwa, R. Guennoun, F. Robert, F. Labombarda, F. Desarnaud, P. Robel, A. F. De Nicola and E. E. Baulieu, Steroid synthesis and metabolism in the nervous system: trophic and protective effects, J. Neurocytol., 2000, 29, 307-326.

53 W. Atkinson, P. Downer, M. Lever, S. T. Chambers and P. M. George, Effects of orange juice and proline betaine on glycine betaine and homocysteine in healthy male subjects, Eur. J. Nutr., 2007, 46, 446-452.

54 A. H. Hainsworth, N. E. Yeo, E. M. Weekman and D. M. Wilcock, Homocysteine, hyperhomocysteinemia and vascular contributions to cognitive impairment and dementia (VCID), Biochim. Biophys. Acta, Mol. Basis Dis., 2016, 1862, 1008-1017.

55 M. Srinivasan, A. R. Sudheer and V. P. Menon, Ferulic acid: Therapeutic potential through its antioxidant property, J. Clin. Biochem. Nutr., 2007, 40, 92-100.

56 A. Sgarbossa, D. Giacomazza and M. di Carlo, Ferulic Acid: A hope for Alzheimer's disease therapy from plants, Nutrients, 2015, 7, 5764-5782.

57 E. Sawicka-Glazer and S. J. Czuczwar, Vitamin C: A new auxiliary treatment of epilepsy?, Pharmacol. Rep., 2014, 66, 529-533.

58 B. Halliwell, Oxidative stress and neurodegeneration: where are we now?, J. Neurochem., 2006, 97, 1634-1658.

59 S. I. Franke, T. N. Guecheva, J. A. Henriques and D. Pra, Orange juice and cancer chemoprevention, Nutr. Cancer, 2013, 65, 943-953.

60 V. Habauzit, I. L. Nielsen, A. Gil-Izquierdo, A. Trzeciakiewicz, C. Morand, W. Chee, D. Barron, P. Lebecque, M. J. Davicco, G. Williamson, E. Offord, V. Coxam and M. N. Horcajada, Increased bioavailability of hesperetin-7-glucoside compared with hesperidin results in more efficient prevention of bone loss in adult ovariectomised rats, Br. J. Nutr., 2009, 102, 976-984.

61 S. Lafay, C. Jan, K. Nardon, B. Lemaire, A. Ibarra, M. Roller, M. Houvenaeghel, C. Juhel and L. Cara, Grape extract improves antioxidant status and physical performance in elite male athletes, J. Sports Sci. Med., 2009, 8, 468-480.

62 L. Pilaczynska-Szczesniak, A. Skarpanska-Steinborn, E. Deskur, P. Basta and M. Horoszkiewicz-Hassan, The influence of chokeberry juice supplementation on the reduction of oxidative stress resulting from an incremental rowing ergometer exercise, Int. J. Sport Nutr. Exercise Metab., 2005, 15, 48-58.

63 F. Dajas, A. C. Andres, A. Florencia, E. Carolina and R. M. Felicia, Neuroprotective actions of flavones and flavonols: mechanisms and relationship to flavonoid structural features, Cent. Nerv. Syst. Agents Med. Chem., 2013, 13, 30-35.

64 S. S. C. Rao, J. Beaty, M. Chamberlain, P. G. Lambert and C. Gisolfi, Effects of acute graded exercise on human colonic motility, Am. J. Physiol.: Gastrointest. Liver Physiol., 1999, 276, G1221-G1226. 
65 F. Gomez-Pinilla, Brain foods: the effects of nutrients on brain function, Nat. Rev. Neurosci., 2008, 9, 568578.

66 J. A. Morgan, F. Corrigan and B. T. Baune, Effects of physical exercise on central nervous system functions: a review of brain region specific adaptations, J. Mol. Psychiatry, $2015,3,3$.
67 G. L. Milne, B. Gao, E. S. Terry, W. E. Zackert and S. C. Sanchez, Measurement of F2- isoprostanes and isofurans using gas chromatography-mass spectrometry, Free Radicals Biol. Med., 2013, 59, 36-44.

68 W. Yan, G. D. Byrd and M. W. Ogden, Quantitation of isoprostane isomers in human urine from smokers and nonsmokers by LC-MS/MS, J. Lipid Res., 2007, 48, 1607-1617. 